\title{
Remifentanil added to sufentanil-sevoflurane anesthesia suppresses hemodynamic and metabolic stress responses to intense surgical stimuli more effectively than high-dose sufentanil-sevoflurane alone
}

\author{
Ingo Bergmann*, Torsten Szabanowski, Anselm Bräuer, Thomas A Crozier, Martin Bauer and José Maria Hinz
}

\begin{abstract}
Background: Even extremely high-doses of the potent opioid, sufentanil, cannot reliably suppress stress responses to intense surgical stimuli such as sternotomy. The chemically related opioid remifentanil with its different pharmacokinetics and binding affinities for delta- and kappa-opioid receptors might be more effective in attenuating these responses.

Methods: ASA I-III patients scheduled for a surgical procedure with sternotomy under balanced anesthesia (sevoflurane and sufentanil $3 \mu \mathrm{g} \cdot \mathrm{kg}^{-1}$ bolus, $0.017 \mu \mathrm{g} \cdot \mathrm{kg}^{-1} \cdot \mathrm{min}^{-1}$ infusion) were randomized into two groups. Patients in the study group were supplemented with remifentanil $\left(2 \mu \mathrm{g} \cdot \mathrm{kg}^{-1}\right.$ bolus, $2-7 \mu \mathrm{g} \cdot \mathrm{kg}^{-1} \cdot \mathrm{min}^{-1}$ infusion) starting ten minutes before sternotomy. Heart rate, arterial blood pressures, cardiac index, ejection fraction, systemic vascular resistance index (SVRI), total body oxygen uptake $\left(\mathrm{VO}_{2}\right)$ and electric dermal response were measured and compared between the groups.

Results: 62 patients were studied (study group 32, control group 30). Systolic and mean arterial blood pressures, SVRI, $\mathrm{VO}_{2}$ and skin conductance increased during sternotomy and sternal spread in the control group but not in the study group. Systolic blood pressure increase: $7.5 \pm 19 \mathrm{mmHg}$ vs. $-3.4 \pm 8.9$ ( $p=0.005) ; \mathrm{VO}_{2}$ increase: $31 \pm 46 \%$ vs. $-0.4 \pm 32 \%$; incidence of systolic blood pressure increase greater than 15 percent: $20 \%$ vs. $3 \%$ ( $p=0.035)$ (control vs. study group).
\end{abstract}

Conclusion: High-dose remifentanil added to sevoflurane-sufentanil anesthesia suppresses the sympathoadrenergic response to sternotomy and sternal spread better than high-dose sufentanil alone.

Trial registration: Clinical Trial number: DRKS 00004327, August 31, 2012

Keywords: Sternotomy, Stress response, Remifentanil, Intraoperative hypertension, Oxygen uptake

\section{Background}

Sympathoadrenergic responses to surgical trauma affect perioperative morbidity and mortality and are particularly undesirable in patients with ischemic or congestive heart disease. Increased blood pressure and oxygen consumption can cause myocardial ischemia and ultimately worsen the patients' perioperative prognosis [1]. High doses of opioid narcotics were shown to provide hemodynamic stability and suppress most reactions to

\footnotetext{
* Correspondence: Ingo.Bergmann@med.uni-goettingen.de
Department of Anaesthesiology, Emergency and Intensive Care Medicine,

* Correspondence: Ingo.Bergmann@med.uni-goettingen.de University of Göttingen Medical School, Robert-Koch Str. 40, 37075 Göttingen, Germany
}

surgical trauma [2-5]. But even sufentanil, administered at up to one hundred-fold the normal anesthetic dose, cannot reliably prevent the responses to sternotomy and sternal spread [6], a stimulus that is known to cause myocardial ischemia [7]. The reason for this is that the maximal effect attainable with sufentanil is insufficient. his effect cannot be increased by administering a even larger dose (ceiling-effect) as shown by the sigmoid plasma concentration-response curve $[8,9]$.

Remifentanil is chemically related to sufentanil [10], but differs from it in several aspects. Remifentanil has an extremely short context-sensitive half time [11] which allows it to be administered in very high doses during 
particularly stressful intraoperative phases without prolonging recovery time $[10,12]$. Remifentanil also has different affinities for cardiac kappa and delta opioid receptors [13]. These receptors are thought to mediate the cardioprotective effect reported for remifentanil [13] and could also possibly be exploited to attenuate the cardiovascular responses that do not respond to the predominantly $\mu$-opioid receptor activation of sufentanil. One possible disadvantage of remifentanil might be its reported link to opioid-induced hyperalgesia $[14,15]$.

We hypothesized that high-dose remifentanil given before and during sternotomy in addition to a balanced high-dose sufentanil-sevoflurane anesthesia could attenuate the cardiovascular and metabolic stress responses.

\section{Methods}

\section{General}

This prospective, randomized double-blinded study was conducted with the approval of our clinical research ethics committee (Universitätsmedizin Göttingen, Ethikkommission 14/2/11, on 29 March 2012). It was registered on August 31, 2012 with the German registry of clinical trials (Deutsches Register für klinische Studien (http://drks-neu. uniklinik-freiburg.de/drks_web/navigate.do?navigationId= trial.HTML\&TRIAL_ID=DRKS00004327) under the trial number DRKS 00004327. The participating patients gave their written consent after having been informed by the principal investigator, Dr. Bergmann, both orally and with written information material.

\section{Patients}

ASA I - III patients scheduled for surgery requiring sternotomy for cardiac surgery were eligible for inclusion. Exclusion criteria were emergency surgery or a preoperative hemoglobin concentration under $10 \mathrm{~g} \mathrm{dL}^{-1}$. After having given written informed consent the patients were randomized to the control or the study group using a computer-generated list (www.randomizer.org). All patients had a balanced anesthesia with high-dose sufentanil and sevoflurane. In addition to these drugs, the patients in the study group were given remifentanil as a continuous infusion in the period before and during sternotomy (see below). Two investigators (IB and TS) performed all anesthetics.

\section{Patient preparations}

Premedication consisted of oral midazolam $7.5 \mathrm{mg}$ given on the ward 20 to 30 minutes before induction of anesthesia. In the operating room an infusion was established via a peripheral vein and the radial artery was cannulated. We attached forehead electrodes for measuring state entropy ( $\mathrm{S} / 5$ monitor, GE Healthcare, Helsinki, Finland) and palmar $\mathrm{Ag} / \mathrm{AgCl}_{2}$ electrodes for measuring skin conductance (Elektrosympathograph 1001, Ingenieurbüro Dr.
Janitzki, Altenbeken, Germany [16]). After induction, a four-lumen central venous catheter and a pulmonary artery catheter were inserted; the latter was positioned with the inflated balloon in wedge position. The transesophageal echocardiography (TEE) probe was introduced and used to assess cardiac filling volumes and measure ejection fractions (fractional area change, FAC, in the transgastric mid short-axis view).

\section{Monitoring}

Heart rate, systolic and mean arterial pressure (SAP, $\mathrm{MAP})$, pulmonary artery pressure (PAP), central venous pressure (CVP), oxygen consumption $\left(\mathrm{VO}_{2}\right)$, Surgical Pleth Index (SPI, see below), entropy (SE and RE) and skin conductance as an indicator of sympathetic nervous system activity were monitored continuously and the data stored for offline analysis by a researcher not involved in data acquisition and blinded to the patient's group. $\mathrm{VO}_{2}$ was measured by indirect calorimetry with the integrated metabolic monitor module of the respirator (Datex Ohmeda M-COVX). Plasma catecholamine concentrations were not determined because they are not reliable indicators of endogenous secretion in this setting, since many patients are routinely given catecholamine infusions during the pre-sternotomy phase, as was the case in the present study

Cardiac output (CO) was measured by thermodilution after intubation, at skin incision for vein harvesting, at sternotomy and ten minutes after sternum spreading. Ice-cold $0.9 \% \mathrm{NaCl}$ was used as injectate. Pulmonary artery wedge pressure (PAWP) and mixed-venous oxygen saturation $\left(\mathrm{SvO}_{2}\right)$ were also measured at these times. Cardiac (CI) and systemic vascular resistance indexes (SVRI) were calculated from the data. Ejection fractions were determined before and after sternotomy. At these time points sufficient crystalloid fluids had been infused to correct any pre-existing hypovolemia and normalize cardiac filling volumes in all patients.

The Surgical Pleth Index (SPI) is an indicator of the body's response to noxious stimuli and thus indirectly of the intensity of analgesia and was used to guide the administration of the remifentanil and sufentanil $[12,17,18]$. The SPI is a dimensionless number between 0 (no response) and 100 (strong response) that is calculated from the heart rate and the pulse-induced volume changes of the finger (photoplethysmography), which are registered by a fingertip sensor. Entropy correlates with the depth of hypnosis [19-21] and was used to adjust the end-tidal sevoflurane concentration. The electrodermal response (EDR) is the change in skin conductance in response to a stimulus and is correlated with the activity of the sympathetic nervous system [22]. A change in skin conductance occurring after the stimulus was recorded as a sympathetic response. 
The study period ended and acquisition of hemodynamic and metabolic data was stopped after the last measurement following sternal spread.

Pain intensity was assessed with a numeric rating scale (NRS) from 1 to 10 during the first twenty-four hours in the intensive care unit by nursing staff blinded to the patient's group allocation. Opioid analgesic consumption data were extracted from the patients' charts.

\section{Anesthesia}

Anesthesia was induced with sufentanil (150 $\mu \mathrm{g}$ bolus for patients under $80 \mathrm{~kg} ; 200 \mu \mathrm{g}$ for patients over $80 \mathrm{~kg}$ ) and midazolam (3-6 mg titrated to hypnotic effect). Rocuronium (1 mg kg-1) was given to facilitate intubation of the trachea. The patients' lungs were ventilated with $60 \%$ oxygen in air in volume-controlled mode with a tidal volume of $6 \mathrm{ml} \mathrm{kg}^{-1}$ and PEEP $7 \mathrm{cmH}_{2} \mathrm{O}$. The respiratory rate was adjusted to keep end-tidal $\mathrm{CO}_{2}$ between 35 and $40 \mathrm{mmHg}$ and sevoflurane was added in an initial age-adapted concentration of $0.5 \mathrm{MAC}$. The chosen sevoflurane concentrations were kept constant by the end-tidal control (ETC.) of the anesthesia machine (Aisys ${ }^{\oplus}$, GE Healthcare).

Anesthesia was maintained in both groups with sevoflurane and a continuous infusion of sufentanil (0.017 $\mu \mathrm{g}$ $\mathrm{kg}^{-1} \mathrm{~min}^{-1}$ ). The end-tidal sevoflurane concentration was adjusted to keep SE below 60 and the difference between RE and SE below 10.

A second bolus injection of $50 \mu \mathrm{g}$ sufentanil was given ten minutes before sternotomy. Immediately following the injection the remifentanil infusion was started in the study group with a $2 \mu \mathrm{g} \mathrm{kg} \mathrm{kg}^{-1}$ loading dose and an initial infusion rate of $2 \mu \mathrm{g} \mathrm{kg} \mathrm{gin}^{-1}$. The infusion rate was adjusted in steps of $0.1 \mu \mathrm{g} \mathrm{kg}^{-1} \mathrm{~min}^{-1}$ to keep the SPI value between 20 and 50 . The infusion rate was also increased by $0.1 \mu \mathrm{g} \mathrm{kg}^{-1} \mathrm{~min}^{-1}$ if the SPI value increased suddenly by more than 10 , even if the SPI was still within the target range. The remifentanil infusion was continued until the last measurement after sternotomy. Additional sufentanil was not administered in the control group because the plasma sufentanil concentrations were on the upper plateau of the concentration-effect curve and a further reduction of SPI could not be achieved with sufentanil.

Mean arterial pressure was kept between 60 and $80 \mathrm{mmHg}$. We increased the inspiratory sevoflurane concentration if MAP persisted in any patient at over $80 \mathrm{mmHg}$. The treatment MAP below $60 \mathrm{mmHg}$ was based on cardiac index, SVRI and cardiac filling volumes and consisted of either the administration of dobutamine or norepinephrine or the infusion of additional fluids. Bradycardia was defined as a heart rate under 45 beats per minute and was treated with an infusion of dobutamine if associated with hypotension.

\section{Statistical analysis}

The data were analyzed with the statistics program Statistica ${ }^{\oplus}$ (StatSoft Europe). Normal distribution was tested with the Kolmogorov-Smirnov test. Normally distributed data were described by mean and standard deviation, non-parametric data by median and range. Categorical data were given as percentages. ANOVA was used to test for changes over time between the groups. Student's $t$ test for paired samples was used to pairs of sampling points in individual groups. Mann-Whitney $U$-test was used for non-parametric data and Fisher's exact test for categorical data. A p-value equal to or less than 0.05 was considered statistically significant.

The primary end-point of the study was a hemodynamic response to sternotomy and sternal spread with the response defined, as in most similar studies, as a greater than $15 \%$ increase in systolic blood pressure. Secondary end-points were other indicators of increased sympathetic nervous system activity, i.e. change in skin conductance, increased cardiac output, increased systemic vascular resistance and increased oxygen consumption.

For calculating the group size required to give an adequately small Type II error (i.e. adequate statistical power) we referred to the average published response rate to sternotomy and sternal spread under high-dose sufentanil anesthesia in studies that used the same definitions as employed in the present study; this is approximately $35 \%$. Two groups with 26 patients each would be required to detect a reduction of the response rate to $10 \%$ with a power of $75 \%$ and a statistical significance level of $5 \%$. We chose to use two groups of 33 patients each to allow for possible dropouts.

\section{Results}

Sixty-six patients were recruited for the study. Four were excluded from the final analysis because of incomplete data sets or withdrawn consent (one in study group, three in control group) (Figure 1: CONSORT flow diagram, Additional file 1). The groups (study group $n=32$; control group $\mathrm{n}=30$ ) did not differ with regard to age, height, body mass index, sex, or ASA classification. All patients were on chronic medication with beta-blockers (Table 1).

The infusion rates and doses of anesthetic drugs are shown in Table 1. The total sufentanil dose administered from induction to sternotomy was the same in the two groups.

The SPI increased significantly in both groups during intubation. The patients in the study group were not receiving remifentanil at this time. During sternotomy and sternal spread, SPI increased significantly from 29 to 58 in the control group but did not change in the patients of the study group, to whom remifentanil was now being administered. The groups differed significantly at this 


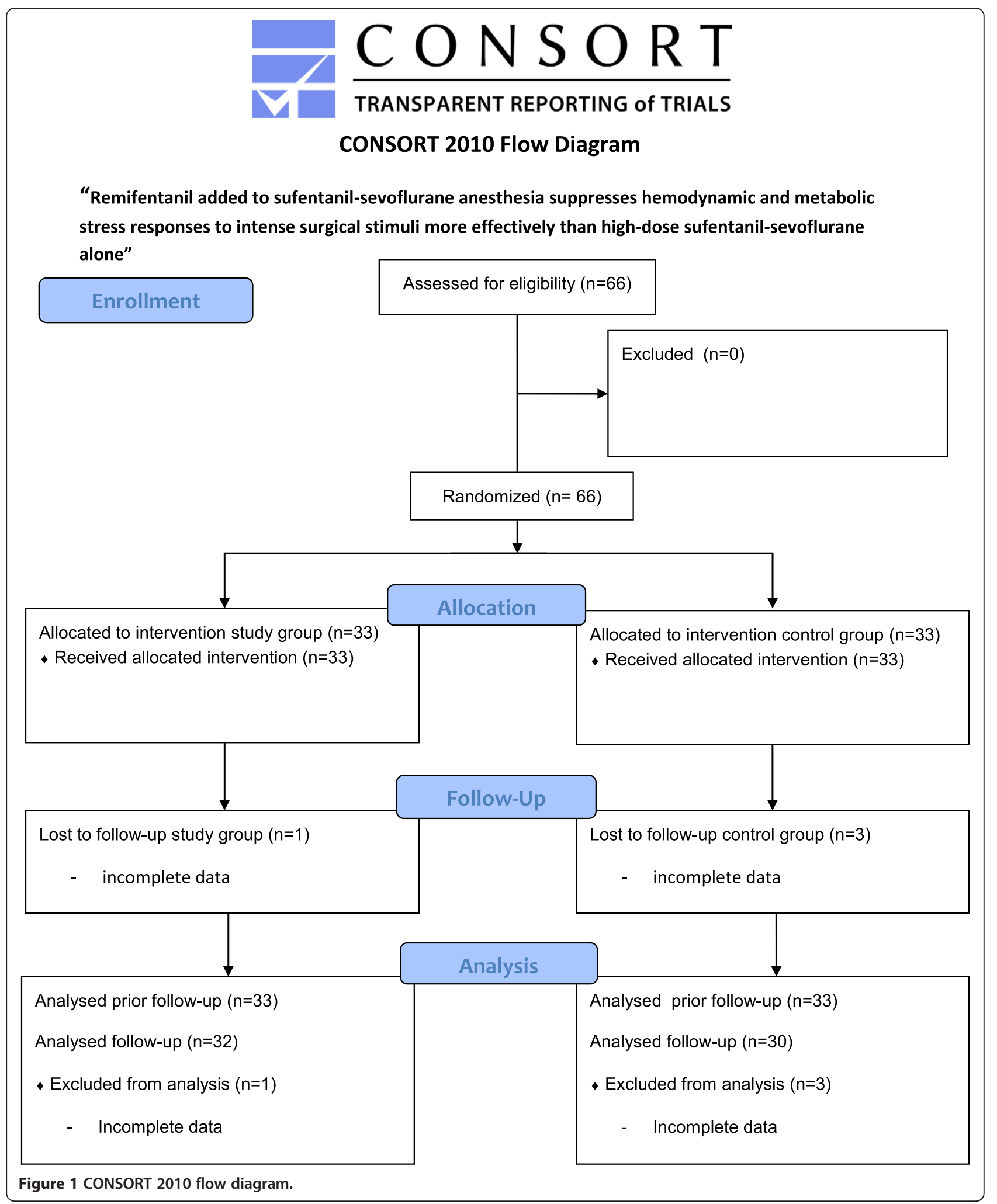

time (see Table 2). State entropy values were within the target range in both groups, but were significantly lower in the study group after starting the remifentanil infusions.
The groups did not differ with regard to the number of patients who showed a sympathetic response to intubation (evidenced by the electrodermal response and SPI), which 
Table 1 Demographic patient data and dosage and consumption of anesthetic drugs

\begin{tabular}{lccc}
\hline & $\begin{array}{c}\text { Study group } \\
\mathbf{n}=\mathbf{3 2}\end{array}$ & $\begin{array}{c}\text { Control group } \\
\mathbf{n}=\mathbf{3 0}\end{array}$ & $\mathbf{p}$ \\
\hline BMI $\left(\mathrm{kg} \mathrm{m}^{-2}\right)$ & $27.3 \pm 4.8$ & $28.9 \pm 5.0$ & 0.18 \\
Male/Female $(\mathrm{n})$ & $19 / 13$ & $24 / 6$ & 0.18 \\
ASA I/II/III ( $\mathrm{n})$ & $0 / 0 / 32$ & $0 / 0 / 30$ & 1.0 \\
Chronic beta-blocker therapy (n) & $32 / 32$ & $30 / 30$ & \\
Remifentanil (maximum infusion rate in $\mu \mathrm{g} \mathrm{kg}^{-1} \mathrm{~min}^{-1}$ ) & \\
before sternotomy & $2.0[0.0-6.0]$ & - & n.a. \\
during sternotomy & $3.0[2.0-7.0]$ & - & n.a. \\
after sternotomy & $2.5[0.3-7.0]$ & - & n.a. \\
Cumulative opioid doses before sternotomy & & \\
Sufentanil ( $\mu$ g) & $345 \pm 68$ & $355 \pm 45$ & 0.5 \\
Remifentanil (mg) & $6.2[1.1-22.1]$ & - & n.a. \\
\hline
\end{tabular}

(means \pm standard deviation, median [range] or count).

n.a. not applicable.

occurred before the remifentanil infusion was started. But the number of patients with increased sympathetic nervous system activity (evidenced by the electrodermal response and SPI) in response to sternotomy was significantly lower in the study group (Table 2).

The courses of blood pressures and heart rate are shown in Table 3. Systolic and mean arterial blood pressure increased significantly less in response to sternotomy in the remifentanil study group. Sternotomy caused a greater than $15 \%$ increase in systolic blood pressure in six patients in the control group (20\%) and only one $(3 \%)$ in the remifentanil group $(\mathrm{p}=0.035)$. Mean arterial pressure reacted similarly with a $63 \%$ response rate in the control group compared to $38 \%$ in the remifentanil group $(\mathrm{p}=0.42)$.

Table 2 Values of surgical Pleth index and electrodermal response

\begin{tabular}{|c|c|c|c|}
\hline & $\begin{array}{l}\text { Study } \\
\text { group } \\
n=32\end{array}$ & $\begin{array}{c}\text { Control } \\
\text { group } \\
n=30\end{array}$ & $p^{*}$ \\
\hline \multicolumn{4}{|l|}{ SPI } \\
\hline $\begin{array}{l}\text { Before surgery before } \\
\text { Intubation }\end{array}$ & $42 \pm 14$ & $42 \pm 17$ & 0.99 \\
\hline after Intubation & $53 \pm 14^{\dagger}$ & $58 \pm 17^{\dagger}$ & 0.23 \\
\hline \multicolumn{4}{|l|}{ During surgery } \\
\hline before sternotomy & $35 \pm 12$ & $29 \pm 18$ & 0.13 \\
\hline during sternotomy & $40 \pm 15$ & $58 \pm 14^{\dagger}$ & $<0.001$ \\
\hline \multicolumn{4}{|l|}{ EDR (n (\%)) } \\
\hline responders to intubation & $12(36 \%)$ & 12 (39\%) & 0.86 \\
\hline responders to sternotomy & $12(37 \%)$ & $24(81 \%)$ & $<0.001$ \\
\hline
\end{tabular}

Table 3 Intraoperative course of heart rate and blood pressure

\begin{tabular}{|c|c|c|c|}
\hline & $\begin{array}{l}\text { Study } \\
\text { group }\end{array}$ & $\begin{array}{l}\text { Control } \\
\text { group }\end{array}$ & $p$ \\
\hline & $\mathrm{n}=32$ & $\mathrm{n}=\mathbf{3 0}$ & \\
\hline \multicolumn{4}{|l|}{ Systolic arterial pressure $(\mathrm{mmHg})$} \\
\hline before intubation & $108 \pm 26$ & $114 \pm 19$ & 0.17 \\
\hline after intubation & $108 \pm 27$ & $115 \pm 22$ & 0.25 \\
\hline During surgery before sternotomy & $100 \pm 17$ & $100 \pm 14$ & 0.99 \\
\hline during sternotomy & $102 \pm 13$ & $115 \pm 25+$ & 0.01 \\
\hline \multicolumn{4}{|l|}{ Mean arterial pressure $(\mathrm{mmHg})$} \\
\hline before intubation & $72 \pm 15$ & $78 \pm 14$ & 0.15 \\
\hline after intubation & $74 \pm 16$ & $77 \pm 14$ & 0.35 \\
\hline During surgery before sternotomy & $72 \pm 9$ & $76 \pm 14$ & 0.2 \\
\hline during sternotomy & $70 \pm 8$ & $79 \pm 13$ & 0.001 \\
\hline \multicolumn{4}{|l|}{ Heart rate $\left(\min ^{-1}\right)$} \\
\hline Before Intubation & $61 \pm 15$ & $60 \pm 14$ & 0.6 \\
\hline After Intubation & $61 \pm 12$ & $61 \pm 13$ & 0.9 \\
\hline During surgery before sternotomy & $54 \pm 10$ & $53 \pm 8$ & 0.9 \\
\hline during sternotomy & $54 \pm 10$ & $54 \pm 10$ & 0.8 \\
\hline
\end{tabular}

Hemodynamic response to sternotomy and sternal spread

Patients with $>15 \%$ increase in systolic $\quad 1[3 \%] \quad 6[20 \%] \quad 0.035$ pressure (n [\%])

$\begin{array}{llll}\text { Average systolic blood pressure change } & -3.4 \pm 8.9 & 7.5 \pm 19 & 0.005\end{array}$

$\begin{array}{llll}\text { Average mean arterial pressure change } & -2.8 \pm 8.2 & 5.9 \pm 18 & 0.02\end{array}$

(means and standard deviation unless otherwise indicated).

Whole body oxygen consumption and systemic vascular resistance index increased significantly in the control group. The ejection fraction (fractional area changes) decreased significantly in the control group (Table 4).

\section{Postoperative pain and opioid analgesic consumption} The median postoperative NRS scores on the day of surgery were 1.5 (range $0-5$ ) in the study group and 2 (range $0-5)$ in the control group $(\mathrm{p}=0.68)$. On the first day after surgery they were 2 (range $0-6$ ) in the study group and 2.5 (range $0-8)$ in the control group $(\mathrm{p}=0.1$ ).

The median postoperative oxycodone consumption was $3 \mathrm{mg}$ (range $0-26.5 \mathrm{mg}$ ) in the study group and $3 \mathrm{mg}$ (range $0-19 \mathrm{mg}$ ) in the control group on the day of surgery $(p=0.64)$. The corresponding doses on the first day after surgery were $3 \mathrm{mg}$ (range $0-23 \mathrm{mg}$ ) and $1.5 \mathrm{mg}$ (range $0-15 \mathrm{mg}$ ) in the study and control groups, respectively, $(\mathrm{p}=0.4)$.

\section{Discussion}

The results of this study indicate that high-dose remifentanil given in addition to balanced anesthesia with high-dose 
Table 4 Extended hemodynamic monitoring data

\begin{tabular}{|c|c|c|c|c|c|c|}
\hline \multirow[b]{3}{*}{ Parameter } & \multicolumn{6}{|c|}{ Measuring time points } \\
\hline & \multicolumn{2}{|c|}{ Before sternotomy } & \multicolumn{2}{|c|}{ During sternotomy } & \multicolumn{2}{|c|}{ After sternotomy } \\
\hline & Study & Control & Study & Control & Study & Control \\
\hline PAPsyst (mmHg) & $29 \pm 9$ & $29 \pm 7$ & $31 \pm 8$ & $33 \pm 8$ & $31 \pm 6$ & $31 \pm 8$ \\
\hline PCWP (mmHg) & $14[3-28]$ & $16[6-26]$ & $13[6-26]$ & $17[8-26]^{*}$ & $13[8-26]$ & $16[8-25]$ \\
\hline $\mathrm{Cl}\left(\mathrm{I} \mathrm{min}^{-1} \mathrm{~m}^{-2}\right)$ & $1.5 \pm 0.4$ & $1.4 \pm 0.3$ & $1.4 \pm 0.3$ & $1.5 \pm 0.4$ & $1.4 \pm 0.3$ & $1.4 \pm 0.3$ \\
\hline EF (\%) & $52 \pm 12$ & $50 \pm 13$ & $52 \pm 12$ & $46 \pm 13^{*}$ & $51 \pm 11$ & $50 \pm 13$ \\
\hline$\triangle \mathrm{EF}$ from before to during sternotomy (\%) & & & $1.4 \pm 10$ & $-7.6 \pm 16^{\dagger}$ & & \\
\hline SVRI & $3176 \pm 1251$ & $3220 \pm 873$ & $3323 \pm 1299$ & $3868 \pm 1062^{\S}$ & $2918 \pm 551$ & $2992 \pm 756$ \\
\hline $\mathrm{VO}_{2}\left(\mathrm{ml} \mathrm{min}{ }^{-1}\right)$ & $144 \pm 25.4$ & $155 \pm 41.1$ & $153 \pm 34.2$ & $186 \pm 49.6^{*}$ & $156 \pm 27$ & $173 \pm 41.1^{*}$ \\
\hline$\Delta \mathrm{VO}_{2}$ from before to during sternotomy (\%) & & & $-0.4 \pm 32$ & $31 \pm 46^{\dagger}$ & & \\
\hline $\mathrm{S}_{\mathrm{v}} \mathrm{O}_{2}$ & $78.3 \pm 6.6$ & $78.3 \pm 5.7$ & $77.7 \pm 5.9$ & $78.6 \pm 6.7$ & $77.3 \pm 9.2$ & $79.0 \pm 5.9$ \\
\hline
\end{tabular}

(mean \pm standard deviation or median [range]).

Abbreviations and symbols: PAPsyst = systolic pulmonary artery pressure; $\mathrm{PCWP}=$ pulmonary capillary wedge pressure; $\mathrm{Cl}=\mathrm{cardiac}$ index; $\mathrm{EF}=$ left vetricular ejection fraction; $\mathrm{SVRI}=$ systemic vascular resistance index; $\mathrm{VO}_{2}=$ oxygen uptake; $\mathrm{S}_{\mathrm{v}} \mathrm{O}_{2}=$ mixed venous oxygen saturation

${ }^{*} \mathrm{p} \leq 0.05 ;{ }^{\dagger} \mathrm{p}<0.01 ;{ }^{\ddagger} \mathrm{p}<0.001$ study group vs. control group; ${ }^{5} \mathrm{p} \leq 0.05$ before vs. during sternotomy (paired $t$-test).

sufentanil and sevoflurane can attenuate the increase in blood pressure and sympathetic nervous system activity induced by sternotomy and sternal spread.

Systolic and mean arterial blood pressures increased significantly in the control group but not in the study group. Six patients in the control group (20\%) but only one in the remifentanil study group $(3 \%)$ had a greater than $15 \%$ increase in systolic blood pressure.

The hemodynamic response rate of $20 \%$ in our control group is similar to that reported by other authors [5,8,23-25]. Philbin et al. observed hemodynamic responses rates up to $50 \%$ with sufentanil doses between 10 and $40 \mu \mathrm{g} \mathrm{kg}^{-1}$ body weight [8]. Thompson et al. using targeted sufentanil plasma concentrations between $3.0 \pm 0.7 \mathrm{ng} \mathrm{ml}^{-1}$ and $7.1 \pm 1.3 \mathrm{ng} \mathrm{ml}^{-1}$ found a greater than $20 \%$ increase in mean arterial pressure in $33 \%$ to $50 \%$ of their patients [24]. These corresponded to total sufentanil doses of $6.8 \pm 1.1 \mu \mathrm{g} \mathrm{kg}^{-1}$ and $20.9 \pm$ $2.0 \mu \mathrm{g} \mathrm{kg}^{-1}$, respectively. Ahonen et al. [23] observed a $20 \%$ hemodynamic response rate to sternotomy in patients with a sufentanil plasma concentration of $0.7 \mathrm{ng} \mathrm{ml}^{-1}$. No dose of sufentanil in any of these studies reduced the response rate to below $20 \%$.

The total sufentanil dose was the same in both groups and was greater than that necessary to obtain full $\mu$ receptor occupation and maximum ceiling effect. In our study, the total sufentanil dose administered during the study period was approximately $4.3 \pm 0.5 \mu \mathrm{g} \mathrm{kg}^{-1}$, which corresponds to a plasma concentration in the range of $2 \mathrm{ng} \mathrm{ml}^{-1}$. This is lower than the dose employed in some studies of the effects of high-dose sufentanil on the response to sternotomy $[8,24]$, and one might argue that one would have obtained the observed effect of remifentanil by simply increasing the sufentanil dose. However, the results of dose-effect studies and the lack of increased effect of high-dose sufentanil contradict this assumption. The dose-response curve of sufentanil follows the typical sigmoid curve with a maximum ceiling effect between 1.25 and $1.4 \mathrm{ng} \mathrm{ml}^{-1}$ (see $[8,9]$ ). The hemodynamic response rate to sternotomy in studies was between $20 \%$ and $60 \%$ in studies using sufentanil plasma concentrations greater than this concentration. This ceiling effect concentration is approximately double the in vitro binding affinity of sufentanil to the $\mu$-opioid receptor [26] and corresponds to a total dose of approximately $2 \mu \mathrm{g} \mathrm{kg}^{-1}$ in patients.

Systemic vascular resistance, a parameter also linked to SNS activity, increased significantly in the control group during sternotomy and sternal spread. The observed simultaneous decrease in ejection fraction is possibly a result of the increased afterload. Stephan et al. described a similar response to sternotomy with increased SVR and reduced cardiac index in patients undergoing myocardial revascularization [27]. This response was not observed in our study group with remifentanil suggesting that remifentanil attenuates or suppresses SNS activation.

The electrodermal response (EDR) is the most direct non-invasive clinical monitor of sympathetic nervous system (SNS) activity. Increased activity stimulates secretion of eccrine sweat glands with a subsequent change in skin conductance $[22,28,29]$. The stimulus of intubation, which was performed before starting the remifentanil infusion, induced an EDR in an identical number of patients (responders) in the two groups. Remifentanil significantly reduced the number of patients with an electrodermal response to sternotomy and chest spreading by $50 \%$ indicating that it suppressed the typical activation of the SNS.

Increased oxygen uptake is evidence of sympathetic nervous system activation [30] and our data suggest that remifentanil suppresses the sympathetic response. 
Plasma catecholamine concentrations are often used to quantify sympathetic nervous system activity but these would have given meaningless results in our study since many of the patients were receiving catecholamine infusions for circulatory support during the study period. These infusions were not responsible for the observed increase in oxygen consumption, since they were neither started nor the infusion rate altered in the period before or during sternotomy.

The inability of sufentanil to reduce the incidence of hemodynamic responders at doses that would assure a saturation of $\mu$-opioid receptors suggests that the observed effect of remifentanil is not mediated by $\mu$ receptors. Remifentanil has a lower affinity for kappa and delta opioid receptors, but a considerable degree of receptor occupation would still have been attained at the plasma concentrations achieved with the high doses applied in this study. The binding affinity of remifentanil is reported to be $2.6 \mathrm{nM}$ for the $\mu$-opioid receptor and 66 $\mathrm{nM}$ for the delta receptor [13]. He and Lee showed that the delta opioid agonist DPDPE acts in a synergistic fashion to reduce the analgesic $\mathrm{ED}_{50}$ of the $\mu$-receptor agonist DAMGO even though binding affinity of DPDPE to delta receptors is at least two orders of magnitude lower than that of DAMGO to $\mu$ receptors [31]. An early study using specific antagonists of delta opioids receptors (naltrindole and naltriben) suggests that sufentanil also has some affinity to delta receptors to produce respiratory depression [32]. Preconditioning mouse hearts with a remifentanil concentration of $10 \mathrm{nM}\left(=3.8 \mathrm{ng} \mathrm{ml} \mathrm{m}^{-1}\right)$ was sufficient to confer cardioprotection and reduce infarct size. This effect was blocked by naltrindol, a delta-opioid receptor antagonist [13]. But while a direct effect on the myocardium might explain the attenuated blood pressure increase, it would not explain the other observed effects on sympathetic nervous system activity. Whether the cardioprotective effects of remifentanil that were demonstrated in mice are relevant for cardiac surgery remains to be determined by further studies.

The depressant effects of remifentanil on hemodynamics have been shown to be reversed by atropine and are considered a stimulatory effect of remifentanil on the parasympathetic nervous system [33,34]. These would counteract sympathetic stimulation, and the hemodynamic effects of remifentanil observed in the present study could be attributed to its vagomimetic actions. This hypothesis is supported by the course of the Surgical Pleth Index (SPI), which was used to guide the administration of remifentanil. The SPI is considered to be a measure of the balance between sympathetic and parasympathetic nervous system (PNS) activity. High intraoperative values correlate with stress [35], while lower values indicate a preponderance of PNS over SNS activity. The remifentanil dose in the study group was increased until the SPI was in an extremely low range corresponding to increased PNS activity.

Some clinicians avoid remifentanil for major surgery because of their concerns about opioid-induced hyperalgesia $[14,15]$. This phenomenon is thought to result from remifentanil acting at delta-opioid receptors to enhance spinal N-methyl-D-aspartate receptor function [36]. In our study, the reported intensity of postoperative pain and the amounts of administered analgesics were the same in the groups with and without remifentanil. Lahtinen et al. [37] also did not find any evidence of opioid-induced hyperalgesia following cardiac surgery when remifentanil was combined with sufentanil.

These findings suggest that remifentanil does not induce clinically relevant hyperalgesia when given for a short period in combination with sufentanil.

\section{Conclusions}

High-dose remifentanil added to balanced high-dose sufentanil-sevoflurane anesthesia can suppress the adrenergic response to sternotomy and sternal spread and attenuate increases in blood pressure, systemic vascular resistance and oxygen uptake. In this setting, remifentanil does not induce postoperative hyperalgesia.

\section{Additional file}

Additional file 1: CONSORT 2010 checklist of information to include when reporting a randomised trial*.

\section{Competing interests}

The study was financed by departmental funds, including the purchase of all devices and materials used in the study. During the past five years none of the authors have received any form of reimbursement or financial or non-financial support from a company that could gain or lose financially from the publication of this manuscript. None of the authors hold any stocks or shares in a company that would gain or lose financially from the publication of this manuscript. None of the authors are applying for any patents related to the content of the manuscript. There are no other competing financial or non-financial interests.

\section{Authors' contribution}

$I B, H J$ and $M B$ designed the study and interpreted the results. IB, TS and $A B$ recruited and treated the patients, TC analysed the stored data offline and performed the statistical analyses together with IB and HJ All authors collaborated in discussing the results and drafting the manuscript. All authors read and approved the final manuscript.

Received: 19 October 2014 Accepted: 12 January 2015 Published: 18 January 2015

\section{References}

1. Wunderlich C, Gossrau G, Wunderlich E, Altmann E. Distinct factors correlating with adverse cardiac events after major vascular surgery. VASA. 2005;34:46-9.

2. Stanley $T H$, Berman $L$, Green O, Robertson D. Plasma catecholamine and cortisol responses to fentanyl-oxygen anesthesia for coronary-artery operations. Anesthesiology. 1980;53:250-3.

3. Bovill JG, Sebel PS, Stanley TH. Opioid analgesics in anesthesia: with special reference to their use in cardiovascular anesthesia. Anesthesiology. 1984;61:731-55. 
4. Giesecke K, Hamberger B, Jarnberg PO, Klingstedt C, Persson B. High- and low-dose fentanyl anaesthesia: hormonal and metabolic responses during cholecystectomy. Br J Anaesth. 1988;61:575-82.

5. Sebel PS, Bovill JG. Cardiovascular effects of sufentanil anesthesia. Anesth Analg. 1982;61:115-9.

6. Philbin DM, Rosow CE, Schneider RC, Koski G, D'Ambra MN. Fentanyl and sufentanil anesthesia revisited: how much is enough? Anesthesiology. 1990;73:5-11.

7. Sonntag H, Stephan H, Lange H, Rieke H, Kettler D, Martschausky N. Sufentanil does not block sympathetic responses to surgical stimuli in patients having coronary artery revascularization surgery. Anesth Analg. 1989;68:584-92.

8. Thomson IR, Henderson BT, Singh K, Hudson RJ. Concentration-response relationships for fentanyl and sufentanil in patients undergoing coronary artery bypass grafting. Anesthesiology. 1998;89:852-61.

9. Brunner MD, Braithwaite $P$, Jhaveri R, McEwan Al, Goodman DK, Smith LR. MAC reduction of isoflurane by sufentanil. $\mathrm{Br} J$ Anaesth. 1994;72:42-6.

10. Komatsu R, Turan AM, Orhan-Sungur M, McGuire J, Radke OC, Apfel CC. Remifentanil for general anaesthesia: a systematic review. Anaesthesia. 2007;62:1266-80.

11. Egan TD. Remifentanil pharmacokinetics and pharmacodynamics. A preliminary appraisal. Clin Pharmacokinet. 1995;29:80-94.

12. Bergmann I, Gohner A, Crozier TA, Hesjedal B, Wiese CH, Popov AF, et al. Surgical pleth index-guided remifentanil administration reduces remifentanil and propofol consumption and shortens recovery times in outpatient anaesthesia. Br J Anaesth. 2013;110:622-8.

13. Zhang $Y$, Irwin MG, Wong TM, Chen M, Cao CM. Remifentanil preconditioning confers cardioprotection via cardiac kappa- and delta-opioid receptors. Anesthesiology. 2005;102:371-8.

14. Guignard B, Bossard AE, Coste C, Sessler DI, Lebrault C, Alfonsi P, et al. Acute opioid tolerance: intraoperative remifentanil increases postoperative pain and morphine requirement. Anesthesiology. 2000;93:409-17.

15. Angst MS, Koppert W, Pahl I, Clark DJ, Schmelz M. Short-term infusion of the mu-opioid agonist remifentanil in humans causes hyperalgesia during withdrawal. Pain. 2003;106:49-57.

16. Janitzki A, Gotte A. Measurements of skin resistance in detecting activity of the sympathetic nervous system in spinal anesthesia. Reg Anaesth. 1986;9:49-53.

17. Bonhomme V, Uutela K, Hans G, Maquoi I, Born JD, Brichant JF, et al. Comparison of the surgical Pleth Index with haemodynamic variables to assess nociception-anti-nociception balance during general anaesthesia. $\mathrm{Br}$ J Anaesth. 2011;106:101-11.

18. Colombo R, Raimondi F, Corona A, Rivetti I, Pagani F, Porta VD, et al. Comparison of the Surgical Pleth Index with autonomic nervous system modulation on cardiac activity during general anaesthesia: A randomised cross-over study. Eur J Anaesthesiol. 2014;31:76-84.

19. Ellerkmann RK, Liermann VM, Alves TM, Wenningmann I, Kreuer S, Wilhelm $W$, et al. Spectral entropy and bispectral index as measures of the electroencephalographic effects of sevoflurane. Anesthesiology. 2004;101:1275-82.

20. Vakkuri A, Yli-Hankala A, Talja P, Mustola S, Tolvanen-Laakso H, Sampson T, et al. Time-frequency balanced spectral entropy as a measure of anesthetic drug effect in central nervous system during sevoflurane, propofol, and thiopental anesthesia. Acta Anaesthesiol Scand. 2004;48:145-53.

21. Viertiö-Oja H, Maja V, Särkelä M, Talja P, Tenkanen N, Tolvanen-Laakso H, et al. Description of the Entropy algorithm as applied in the Datex-Ohmeda S/5 Entropy Module. Acta Anaesthesiol Scand. 2004;48:154-61.

22. Storm H, Myre K, Rostrup M, Stokland O, Lien MD, Raeder JC. Skin conductance correlates with perioperative stress. Acta Anaesthesiol Scand. 2002;46:887-95.

23. Ahonen J, Olkkola KT, Hynynen M, Seppälä T, Ikävalko H, Remmerie B, et al. Comparison of alfentanil, fentanyl and sufentanil for total intravenous anaesthesia with propofol in patients undergoing coronary artery bypass surgery. Br J Anaesth. 2000;85:533-40.

24. Thomson IR, Moon M, Hudson RJ, Rosenbloom M. Does sufentanil concentration influence isoflurane requirements during coronary artery bypass grafting? J Cardiothorac Vasc Anesth. 1999;13:9-14.

25. de Lange S, Boscoe MJ, Stanley TH, Pace N. Comparison of sufentanil-O2 and fentanyl-02 for coronary artery surgery. Anesthesiology. 1982;56:112-8.
26. Zhu J, Xue JC, Law PY, Claude PA, Luo LY, Yin J, et al. The region in the mu opioid receptor conferring selectivity for sufentanil over the delta receptor is different from that over the kappa receptor. FEBS Lett. 1996;384:198-202.

27. Stephan H, Sonntag H, Schenk HD, Kettler D, Khambatta HJ. Effects of propofol on cardiovascular dynamics, myocardial blood flow and myocardial metabolism in patients with coronary artery disease. $\mathrm{Br} J$ Anaesth. 1986:58:969-75.

28. Edelberg R. Electrical Properties Of The Skin. In: Brown CC, editor. Methods in Psychophysiology. Baltimore: Williams \& Wilkins; 1967. p. 1-53.

29. Lidberg L, Wallin BG. Sympathetic skin nerve discharges in relation to amplitude of skin resistance responses. Psychophysiology. 1981;18:268-70.

30. Ensinger $\mathrm{H}$, Weichel $\mathrm{T}$, Lindner KH, Grunert A, Ahnefeld FW. Effects of norepinephrine, epinephrine, and dopamine infusions on oxygen consumption in volunteers. Crit Care Med. 1993;21:1502-8.

31. He L, Lee NM. Delta opioid receptor enhancement of mu opioid receptorinduced antinociception in spinal cord. J Pharmacol Exp Ther. 1998;285:1181-6.

32. Freye $E$, Latasch $L$, Portoghese PS. The delta receptor is involved in sufentanil-induced respiratory depression-opioid subreceptors mediate different effects. Eur J Anaesthesiol. 1992;9:457-62.

33. Fattorini F, Romano R, Ciccaglioni A, Pascarella MA, Rocco A, Mariani V, et al. Effects of remifentanil on human heart electrical system. A transesophageal pacing electrophysiological study. Minerva Anestesiol. 2003;69:673-7.

34. Shinohara K, Aono H, Unruh GK, Kindscher JD, Goto H. Suppressive effects of remifentanil on hemodynamics in baro-denervated rabbits. Can J Anaesth. 2000;47:361-6.

35. Chen X, Thee C, Gruenewald M, Wnent J, Illies C, Hoecker J, et al. Comparison of surgical stress index-guided analgesia with standard clinica practice during routine general anesthesia: a pilot study. Anesthesiology. 2010;112:1175-83.

36. Zhao M, Joo DT. Enhancement of spinal N-methyl-D-aspartate receptor function by remifentanil action at delta-opioid receptors as a mechanism for acute opioid-induced hyperalgesia or tolerance. Anesthesiology. 2008;109:308-17.

37. Lahtinen P, Kokki H, Hynynen M. Remifentanil infusion does not induce opioid tolerance after cardiac surgery. J Cardiothorac Vasc Anesth. 2008;22:225-9.

doi:10.1186/1471-2253-15-3

Cite this article as: Bergmann et al:: Remifentanil added to sufentanilsevoflurane anesthesia suppresses hemodynamic and metabolic stress responses to intense surgical stimuli more effectively than high-dose sufentanil-sevoflurane alone. BMC Anesthesiology 2015 15:3.

\section{Submit your next manuscript to BioMed Central and take full advantage of:}

- Convenient online submission

- Thorough peer review

- No space constraints or color figure charges

- Immediate publication on acceptance

- Inclusion in PubMed, CAS, Scopus and Google Scholar

- Research which is freely available for redistribution 